\title{
Diabetic retinopathy: variations in patient therapeutic outcomes and pharmacogenomics
}

This article was published in the following Dove Press journal:

Pharmacogenomics and Personalized Medicine

12 December 2014

Number of times this article has been viewed

\section{Aniruddha Agarwal \\ Mohamed K Soliman \\ Yasir J Sepah \\ Diana V Do \\ Quan Dong Nguyen}

Ocular Imaging Research and Reading Center, Stanley M. Truhlsen Eye Institute, University of Nebraska Medical Center, Omaha, USA
Correspondence: Quan Dong Nguyen University of Nebraska Medical Center, 985540 Nebraska Medical Center, Omaha, NE 68198-5540, USA

$\mathrm{Tel}+\mathrm{I} 4025594276$

Fax + I 4025595514

Email quan.nguyen@unmc.edu

\begin{abstract}
Diabetes and its microvascular complications in patients poses a significant challenge and constitutes a major health problem. When it comes to manifestations in the eye, each case of diabetic retinopathy (DR) is unique, in terms of the phenotype, genotype, and, more importantly, the therapeutic response. It is therefore important to identify factors that distinguish one patient from another. Personalized therapy in DR is a new trend aimed at achieving maximum therapeutic response in patients by identifying genotypic and phenotypic factors that may result in less than optimal response to conventional therapy, and consequently, lead to poorer outcome. With advances in the identification of these genetic markers, such as gene polymorphisms and human leucocyte antigen associations, as well as development of drugs that can target their effects, the future of personalized medicine in DR is promising. In this comprehensive review, data from various studies have been analyzed to present what has been achieved in the field of pharmacogenomics thus far. An insight into future research is also provided.
\end{abstract}

Keywords: personalized medicine, therapeutic variation, genomic markers, genotype, phenotype, VEGF mutation, polymorphism, linkage, mutation, responder

\section{Introduction}

Diabetes is a major health problem that is frequently associated with long-term microvascular complications. The number of people suffering from diabetes (approximately 366 million in 2011 worldwide) is expected to reach approximately 552 million by the year 2030. Diabetic retinopathy (DR) and its complications are responsible for legal blindness in as many as $2.6 \%$ of the population worldwide, in patients diagnosed with both type I and II diabetes. ${ }^{1,2}$

There is large variation in the incidence and severity of visual loss and other complications associated with DR. For example, the incidence of vitreous hemorrhage in patients with DR ranges from $17 \%$ to $63 \%{ }^{3}$ Similarly, the prevalence of diabetic macular edema (DME) ranges from $0.85 \%$ to $12.3 \%$ among patients with diabetes. ${ }^{4}$ The current standard of care, ie, anti-vascular endothelial growth factor (anti-VEGF) therapy, has shown a significant improvement ( $\geq 3$ lines visual acuity) in only $44.8 \%$ with $0.3 \mathrm{mg}$ ranibizumab in the RISE study, ${ }^{5}$ while $55.2 \%$ patients receiving the same therapy failed to show a similar response. Multiple factors contributing to this variability in response have been studied. It has been proposed that, in addition to environmental factors, genetic makeup of patients may play a role in such variability.

In this review, we explore the developments in the field of pharmacogenomics concerning DR. The analysis may enable clinician-scientists to understand the possible 
mechanisms behind individual variations in response to standard therapeutic interventions in patients with DR.

\section{Methods}

A systematic review of the literature was performed using the United States National Library of Medicine (PubMed), Ovid search engine, and the Medline database to retrieve the literature on the phenotypes and genotypes in DR, genetic basis of patient-to-patient variation in response, and pharmacogenomics. The keywords and MESH headings used were as follows: diabetic retinopathy, genotype, phenotype, polymorphism, linkage, mutation, and responder. Additional articles were also obtained by studying the reference list of these articles. Only articles published in English were included for the review.

In the literature review, both prospective and retrospective studies were included. Studies focusing on patients developing DR as a microvascular complication in both type 1 and type 2 diabetes were included. Studies including various ethnic groups were included in order to ensure comprehensive data analysis. Data from larger clinical trials were also obtained.

\section{Results}

\section{Established therapy} for diabetic retinopathy

Systemic control of the underlying risk factors, ie, hyperglycemia, hypertension, and hyperlipidemia, has been shown to reduce the risk of progression of DR. ${ }^{6}$ Local therapies, which include laser photocoagulation, intravitreal or periocular steroids, and anti-VEGF, on the other hand, are mainly used for the management of DME. ${ }^{7}$ Currently, the use of anti-VEGF agents is gaining popularity and becoming the standard of care for management of DME owing to its favorable outcome. ${ }^{8}$ Thus, the mainstay of therapy for DR that is manifested by DME, among other complications, is periodic intravitreal injections of anti-VEGF. ${ }^{9}$ Such therapy is aimed at antagonizing VEGF and its downstream effects.

Among the various pharmacologic agents used, bevacizumab is a humanized murine monoclonal antibody that binds to all isoforms of VEGF-A. Ranibizumab is a smaller molecule with high binding affinity to VEGF-A ${ }^{10}$ and is approved for treatment of DME by the United States Food and Drug Administration (FDA). Pegaptanib sodium is an aptamer specifically inhibiting the VEGF-A 165 isoform, and aflibercept is a human fusion protein incorporating ligandbinding elements from VEGF receptors and the Fc region of an IgG1 molecule. Aflibercept has been recently approved for the treatment of DME by the FDA. Aflibercept offers similar efficacy as the other anti-VEGF agents with the potential advantage of less frequent dosing. ${ }^{11}$

In addition to anti-VEGF therapy, intravitreal and periocular injections of corticosteroids and laser photocoagulation have been used to treat DR as well.

\section{Concerns with established therapy for diabetic retinopathy}

Clinical trials have demonstrated marked variations in response to anti-VEGF therapy in DME. For instance, with $0.3 \mathrm{mg}$ ranibizumab, $44.8 \%$ of patients gained $>3$ lines on the EDTRS chart at 24 months, with the rest of the study subjects showing less than optimal response in the RISE study, whereas $34 \%$ patients receiving $0.3 \mathrm{mg}$ ranibizumab demonstrated an improvement of $>3$ lines on ETDRS chart in the RIDE study. ${ }^{5}$ In both trials, there were few patients that showed loss of $>15$ letters, ie, six out of 250 patients in RISE and seven out of 252 patients in RIDE study. Similarly, trials have also documented the efficacy of bevacizumab in patients with DME. The bevacizumab or laser therapy (BOLT) study demonstrated that, in patients receiving intravitreal injections of bevacizumab, there was $>3$ EDTRS lines improvement in visual acuity in $39 \%$ of patients. ${ }^{12}$ In the DA VINCI study, $34 \%$ of the patients showed a significant level of visual acuity improvement following therapy with aflibercept. ${ }^{13}$ Variation of treatment response with anti-VEGF therapy has also been demonstrated in other retinal diseases such as age-related macular degeneration. In the Comparison of Age-Related Macular Degeneration Treatments Trials (CATT), 34.2\% and $31.3 \%$ patients showed an improvement of $>15$ letters following treatment with monthly ranibizumab and bevacizumab, respectively. ${ }^{14}$

The results of these major clinical trials indicate that, among patients with DR and DME, there are asymmetric responses. There is large variation in the clinical response, and many patients do not demonstrate satisfactory levels of visual acuity improvement (Table 1).

\section{Phenotype variation in diabetic retinopathy}

Available data suggest that phenotypic variation occurs in patients with DR. Multimodal imaging has demonstrated that some patients may present with certain features on biomicroscopy and indirect ophthalmoscopy, such as rates of microaneurysm accumulation and foveal avascular zone alterations that may be associated with worse 
Table I Visual outcome analysis in patients with diabetic retinopathy enrolled in various clinical trials.

\begin{tabular}{|c|c|c|c|c|c|}
\hline $\begin{array}{l}\text { Clinical } \\
\text { trial }\end{array}$ & $\begin{array}{l}\text { Pharmacologic agent } \\
\text { with dose }\end{array}$ & $\begin{array}{l}\text { Gain of } \geq 3 \\
\text { lines (\%) }\end{array}$ & $\begin{array}{l}\text { Loss of } \geq 3 \\
\text { lines }(\%)\end{array}$ & $\begin{array}{l}\text { No significant change (gain } \\
\text { or loss of }<3 \text { lines) (\%) }\end{array}$ & $\begin{array}{l}\text { Study duration } \\
\text { (months) }\end{array}$ \\
\hline \multicolumn{6}{|c|}{ Trials with intravitreal anti-vascular endothelial growth factor (anti-VEGF) therapy } \\
\hline \multirow[t]{3}{*}{ RISE $^{5}$} & Ranibizumab & & & & 24 \\
\hline & $0.3 \mathrm{mg}$ & 44.8 & 2.4 & 52.8 & \\
\hline & $0.5 \mathrm{mg}$ & 39.2 & 2.4 & 58.4 & \\
\hline \multirow[t]{3}{*}{$\mathrm{RIDE}^{5}$} & Ranibizumab & & & & 24 \\
\hline & $0.3 \mathrm{mg}$ & 33.6 & 1.6 & 64 & \\
\hline & $0.5 \mathrm{mg}$ & 45.7 & 4 & 50.3 & \\
\hline \multirow[t]{3}{*}{ VIVID 15} & Aflibercept & & & & 12 \\
\hline & 2 mg 4-weekly & 32.4 & 0.7 & 66.9 & \\
\hline & 2 mg 8-weekly & 33.3 & 0 & 66.7 & \\
\hline \multirow[t]{3}{*}{ VISTA $^{15}$} & Aflibercept & & & & 12 \\
\hline & 2 mg 4-weekly & 41.6 & 0.6 & 57.8 & \\
\hline & 2 mg 8-weekly & 31.1 & 0.7 & 68.2 & \\
\hline \multirow[t]{2}{*}{$\mathrm{BOLT}^{12}$} & Bevacizumab & & & & 24 \\
\hline & $1.25 \mathrm{mg}$ & 32 & 0 & 68 & \\
\hline \multirow[t]{2}{*}{ DA VINCI' } & Aflibercept & & & & 12 \\
\hline & $2 \mathrm{mg}$ & 34 & 0 & 66 & \\
\hline \multirow[t]{2}{*}{ READ $2^{16}$} & Ranibizumab & & & & 24 \\
\hline & $0.5 \mathrm{mg}$ & 24 & 3 & 73 & \\
\hline RESOLVE ${ }^{17}$ & $\begin{array}{l}\text { Ranibizumab (pooled } \\
\text { analysis of } 0.3 \text { and } 0.5 \mathrm{mg} \text { ) }\end{array}$ & 33 & 3 & 64 & 12 \\
\hline \multirow[t]{2}{*}{ RESTORE $^{18}$} & Ranibizumab & & & & 12 \\
\hline & $0.5 \mathrm{mg}$ & 22.6 & 0.9 & 76.5 & \\
\hline \multicolumn{6}{|c|}{ Trials with intravitreal steroid therapy } \\
\hline \multirow[t]{3}{*}{ FAME $^{19}$} & Fluocinolone & & & & 24 \\
\hline & $0.2 \mu \mathrm{g} / \mathrm{day}$ & 28.7 & 0 & 71.3 & \\
\hline & $0.5 \mu \mathrm{g} / \mathrm{day}$ & 28.6 & 0 & 71.4 & \\
\hline \multirow[t]{3}{*}{ MEAD ${ }^{20}$} & Dexamethasone & & & & 36 \\
\hline & $0.7 \mathrm{mg}$ & 22.2 & 0 & 77.8 & \\
\hline & $0.35 \mathrm{mg}$ & 18.4 & 0 & 81.6 & \\
\hline
\end{tabular}

visual prognosis. ${ }^{21}$ In this 3-year follow-up study performed on 14 eyes with type 2 diabetes, the level of DR was graded by the Wisconsin Card-Sorting Test. Areas of abnormally increased hyperfluorescence were analyzed at baseline and follow-up visits after stabilization of mean $\mathrm{HbA}_{1 \mathrm{c}}$ levels. Based on the intensity and persistence of the leakage sites, a genetic basis for this phenotypic variation in DR was suggested by the authors.

Studies with larger cohorts were subsequently performed to validate the results of the previous study. ${ }^{22,23}$ A prospective study ${ }^{22}$ including 410 patients with type 2 diabetes was conducted to follow up the patients for 2 years or until the time they developed macular edema. The results of this study demonstrated the presence of three distinct phenotypes of DR. Phenotype A was identified with lowest microaneurysm turnover and central subfoveal thickness. Phenotype B was identified with higher central subfield retinal thickness, whereas phenotype $\mathrm{C}$ had higher microaneurysms turnover but variable macular thickness. A study involving patients with type 1 diabetes suggested that the genetic makeup may affect the breakdown of the blood-retinal barrier or pericyte apoptosis, resulting in different phenotypes of DR. ${ }^{24}$

As an example, Figure 1 shows the differences in progression of DR in two patients. In the first patient (panels A and B), there is an increased turnover of microaneurysms over time, whereas the second patient (panels C and D) has an increased leakage on fluorescein angiography and thickness over a period of 3 months without much microaneurysm turnover.

The FIND-Eye study ${ }^{25}$ in 2008 suggested increased severity of DR in individuals predisposed genetically to more microvascular complications, including diabetic nephropathy. A number of ethnic groups were included in this study, such as American Indians, European Americans, African Americans, and Mexican Americans. Hereditability of the severity of retinopathy was assessed by sibling analysis. Another study that retrospectively reviewed charts of both Black and Latino diabetic patients demonstrated that Latinos may be at a greater risk for a specific retinopathy phenotype characterized by extravasation of intraretinal hemorrhages and poorer prognosis. ${ }^{26}$ 


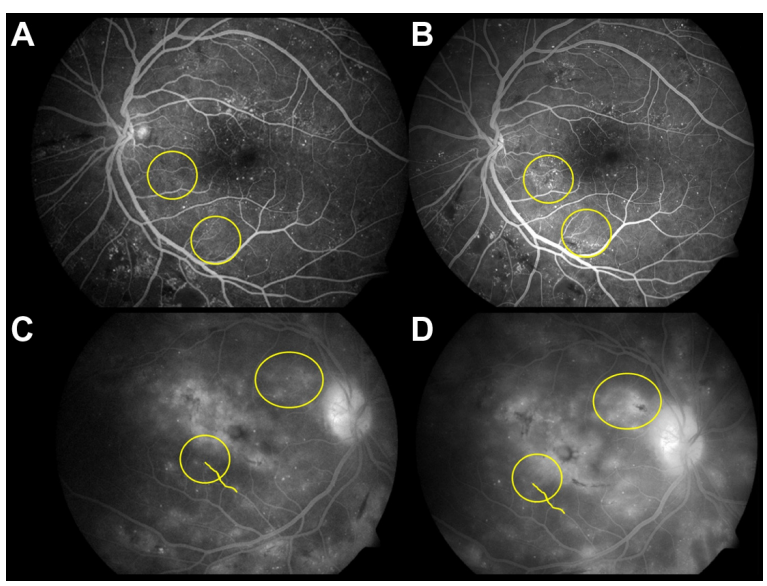

Figure I Characteristic differences in the phenotype of diabetic retinopathy (DR) in two patients.

Notes: Panels $\mathbf{A}$ and $\mathbf{B}$ show fluorescein angiography of one patient with type 2 diabetes mellitus who presented with a nonproliferative DR (panel A). The area marked with yellow circle shows the absence of microaneurysms at that location during the initial presentation. After 3 months, the same area, marked with a yellow circle, shows development of new microaneurysms (panel B), without much increase in leakage on fluorescein angiography. Panels $\mathbf{C}$ and $\mathbf{D}$ show fluorescein angiography of another patient with type 2 diabetes mellitus (taken at the same time interval). Panel $C$ shows the angiography at presentation; areas are marked with yellow circles to demonstrate an increase in the area of leakage (the vessels are traced with yellow lines to allow comparison) and thickness over a period of 3 months (panel D) without significant increase in the microaneurysm turnover.

Conclusive data that identify specific complication risks for each ethnic group are not available.

Morphometric analysis of eyes of patients with DR have shown that certain features on spectral domain optical coherence tomography imaging, such as disruption of photoreceptor inner segment-outer segment junction, can significantly decrease retinal sensitivity. Further studies are required to correlate genetic basis of this phenotype observation. ${ }^{27}$

There is increasing evidence for the genetic basis for phenotypic variations in patients with DR. ${ }^{28}$ Differences in phenotypes may result in increased risk of progression of the disease and visual loss due to higher levels of ischemia and VEGF release. ${ }^{16,29}$ With advancement in clinical examination techniques and imaging modalities, it may be possible to identify more phenotypic variations in DR. Early identification of such a cohort of patients may enable clinicians to prepare for more aggressive therapy in order to salvage vision.

\section{Genotype variation in diabetic retinopathy}

Data from a number of studies suggest the presence of various genetic polymorphisms in susceptibility to DR. There are a number of studies that provide evidence to the presence of various pathogenetic factors, including activity of aldose reductase (AR) and protein kinase $\mathrm{C}$ as well as processes such as glycation, platelet adhesion, and aggregation.

\section{Genetic basis of morphological variation in diabetic retinopathy}

Results from twin studies ${ }^{30}$ and various clinical trials such as the Diabetic Control and Complications Trial (DCCT) suggest genetic polymorphisms that may play an important role in manifestations of DR, such as familial clustering of proliferative DR. ${ }^{31}$ It has been shown that only about half the number of patients diagnosed with nonproliferative DR progress to the proliferative disease. ${ }^{30,31}$ Further investigations into the genetic factors that influence the manifestations of retinopathy have revealed human leucocyte antigen (HLA) associations and single nucleotide polymorphisms (SNPs), which may contribute to the initiation or promotion of inflammatory cascade. ${ }^{32}$

\section{Genome-wide association studies}

One of the strategies to identify genetic predisposition to severe DR is genome-wide association studies (GWAS). Using this data, millions of common polymorphisms can be identified in the human genome. Following the successful GWAS for age-related macular degeneration, similar studies have been performed for various populations for DR.

Two large cohorts including patients with type 1 diabetes, the Epidemiology of Diabetes Intervention and Control Trial and the Genetics of Kidney in Diabetes studies, did not find any genome-wide association except a relationship between severe DR and the SNP rs476141..$^{32}$ This SNP is located between the AKT3 and ZNF238 genes that may play a role in cell survival, insulin signaling, and angiogenesis. The Wisconsin Epidemiologic Study of Diabetic Retinopathy (WESDR) found a new potential SNP rs 4865047 located in the CEP125 gene associated with severe DR. ${ }^{33}$

In the Taiwanese population, five loci have been identified in patients who are susceptible for the development of DR. These loci include $P L X D C 2$ and $A R H G A P 22$, which play a role in capillary endothelial proliferation and permeability. ${ }^{34}$ In a study with Mexican-American population, 32 SNPs were identified from 11 regions in patients with DR with modest association. These SNPs belonged to loci from genes that are usually not associated with DR. ${ }^{35}$

A large collaborative study with European-American population, the Candidate-gene Association Resource (CARe), comprised more than 2,500 subjects with type 2 diabetes. In this study, polymorphisms associated with DR identified included certain SNPs in the P-selectin (SELP) gene. These polymorphisms were associated with increased severity of DR. However, the results of this study were not replicable in studies involving other ethnic and racial groups. ${ }^{33}$ 
Thus, polymorphisms involving the selectin genes have not conclusively been shown to be associated with severe DR.

More studies that can validate data and include larger cohorts have been possible because of rapid advances in technology and means to identify genetic variations. However, presently, GWAS have various limitations. These include replicability of data due to ethnic variations in polymorphisms. The commercial arrays can identify only rare, low-frequency variants. Larger studies with different ethnic groups may be required to provide stronger statistical support for confirming association. ${ }^{32}$

\section{Linkage studies and HLA association}

Linkage analysis helps in the identification of alleles that may predispose to the development of more aggressive form of DR. Linkage analysis was carried out in Pima Indians to identify susceptibility genes for DR. ${ }^{36}$ In this study, a region close to angiotensin II receptor gene AGTRI located on chromosome 3 was identified to be associated with retinopathy. Familial aggregation of severe DR was linked to chromosome 1 in another study. ${ }^{37}$ However, further studies are required to conclusively establish any association.

Several studies have also attempted to identify associations between HLA and severity of DR. Literature supports the association between HLA DR4 and DR3 phenotypes to be associated with proliferative DR. The odds of developing proliferative retinopathy among individuals with HLA-DR $3 / 0$ are 3.74 times the control arm, with the true population effect being $1.8-7.8$ times. $^{38,39}$

\section{Candidate gene studies}

Candidate genes encoding proteins that may play an important role in the pathogenesis of DR have been studied extensively in order to identify their polymorphisms as potential pharmacogenetic markers. An attempt to identify these markers in DR in individuals with diabetes has been made and involved various population subgroups. Certain polymorphisms belong to pathways that are distinct from VEGF.

Apart from VEGF, certain candidate genes such as aldose reductase $(A R),{ }^{40}$ endothelial nitric oxide synthase (eNOS), ${ }^{41}$ receptor for advanced glycation end products $(R A G E),{ }^{42}$ and erythropoietin $(E P O)^{43}$ genes have been studied extensively in various ethnic groups. Polymorphisms in these candidate genes can potentially affect various metabolic pathways, thereby increasing the risk of severe DR. For example, mutations in the methylenetetrahydrofolate reductase (MTHFR) gene are associated with high plasma homocysteine levels, ${ }^{44,45}$ increasing the risk of proliferative DR. ${ }^{46-48}$ There is, however, no clear consensus on the exact role of various candidate gene polymorphisms, and further research in this direction is warranted.

Table 2 lists the important potential pharmacogenetic markers of severe DR based on evidences from various

Table 2 Possible pharmacogenetic markers for diabetic retinopathy

\begin{tabular}{|c|c|c|}
\hline Gene & Variation & Clinical outcome \\
\hline$\overline{A C E}$ & $2350 \mathrm{G} / \mathrm{A}$ & $\begin{array}{l}\text { Associated with development of diabetic } \\
\text { retinopathy in Chinese population }{ }^{49}\end{array}$ \\
\hline AGTRI & All $66 \mathrm{C}$ & $\begin{array}{l}\text { Increased risk of diabetic retinopathy and } \\
\text { nephropathy }{ }^{50}\end{array}$ \\
\hline$A R$ & $-106 C C$ & $\begin{array}{l}\text { Increased risk of proliferative retinopathy } \\
\text { in Caucasian-Brazilians }{ }^{51}\end{array}$ \\
\hline $\mathrm{CFH}$ & $\begin{array}{l}\text { rs } 800292 \\
\text { rs } 1048709\end{array}$ & $\begin{array}{l}\text { Important role in pathogenesis and } \\
\text { development of diabetic retinopathy }{ }^{52}\end{array}$ \\
\hline CHN2 & rs 1002630 & $\begin{array}{l}\text { Increased risk of nonproliferative diabetic } \\
\text { retinopathy in Taiwanese individuals }{ }^{53}\end{array}$ \\
\hline$E L$ & c.584C $>T$ & $\begin{array}{l}\text { Increased risk factor for developing } \\
\text { severe, sight-threatening proliferative } \\
\text { disease }^{54}\end{array}$ \\
\hline eNOS & $4 b / b$ & $\begin{array}{l}\text { Confers an increased risk of severe } \\
\text { diabetic retinopathy }\end{array}$ \\
\hline$E P O$ & $\begin{array}{l}r s / 617640 \\
r s 507392 \\
r s 55 / 238\end{array}$ & $\begin{array}{l}\text { Increased risk of development of } \\
\text { proliferative diabetic retinopathy in } \\
\text { American and Australian population }{ }^{56}\end{array}$ \\
\hline $\begin{array}{l}\text { ITGA2 } \\
\text { ITGB3 }\end{array}$ & $\begin{array}{l}B g I I I \\
P I A I / A 2\end{array}$ & Increased risk of diabetic retinop \\
\hline MCP-I & c. $25 / 8 \mathrm{G} / \mathrm{G}$ & $\begin{array}{l}\text { Increased susceptibility to proliferative } \\
\text { diabetic retinopathy in type } 2 \text { diabetes } \\
\text { patients }^{58}\end{array}$ \\
\hline MTHFR & C667T & $\begin{array}{l}\text { Development of microangiopathic } \\
\text { changes in patients with Type } 2 \text { diabetes }{ }^{59}\end{array}$ \\
\hline$O P G$ & $\begin{array}{l}r s 20736 / 8 \\
r s 3 / 34069\end{array}$ & $\begin{array}{l}\text { Increased risk of development of diabetic } \\
\text { retinopathy }{ }^{60}\end{array}$ \\
\hline RAGE & $\begin{array}{l}1704 \mathrm{G} / \mathrm{T} \\
2245 \mathrm{G} / \mathrm{A}\end{array}$ & $\begin{array}{l}\text { Increased pro-inflammatory response in } \\
\text { patients with diabetic retinopathy }{ }^{61,62}\end{array}$ \\
\hline SELP & $\begin{array}{l}r s / 2708942 \\
r s 9806929 \\
r s 4783824\end{array}$ & $\begin{array}{l}\text { Development of diabetic retinopathy in } \\
\text { patients with type } 2 \text { diabetes }{ }^{63}\end{array}$ \\
\hline TCF7L2 & rs7903/46 & $\begin{array}{l}\text { This polymorphism plays an important } \\
\text { role in development of diabetes mellitus. } \\
\text { But contribution in development of } \\
\text { retinopathy may be small }{ }^{64}\end{array}$ \\
\hline UCPI & $-3826 A / G$ & Increased risk of proliferative diabetic \\
\hline UCP2 & A Val Ins & retinopathy with both the genes ${ }^{65,66}$ \\
\hline VEGF & $\begin{array}{l}-2578 \mathrm{Cl} / \mathrm{A} \\
\text { I } 498 \mathrm{C} / \mathrm{T}(-460 \mathrm{C} / \mathrm{T}) \\
-634 \mathrm{G} / \mathrm{C}(405 \mathrm{G} / \mathrm{C}) \\
+936 \mathrm{C} / \mathrm{T}\end{array}$ & $\begin{array}{l}\text { Enhanced VEGF expression } \\
\text { Increased susceptibility of retinopathy in } \\
\text { various population studies }{ }^{67 a}\end{array}$ \\
\hline
\end{tabular}

Note: Meta-analysis.

Abbreviations: ACE, angiotensin converting enzyme; AGTR, angiotensin ॥ receptor; AR, aldose reductase; $\mathrm{CFH}$, complement factor $\mathrm{H}$; $\mathrm{CHN} 2=\mathrm{NOR}$, neuron-derived orphan receptor; EL, endothelial lipase; eNOS, endothelial nitric oxide synthase; EPO, erythropoietin; ITGA/B, integrin $A / B ; M C P I$, monocyte chemotactic protein I, MTHFR, methylenetetrahydrofolate reductase; OPG, osteoprotegrin; RAGE, receptor for advanced glycation end products; SELP, selectin P; TCF7L2, transcription factor 7 like 2; UCP, uncoupling protein; VEGF, vascular endothelial growth factor. 
population case-control trials. Data from meta-analysis have also been included, where available. With more research, our knowledge of genetic markers is going to expand.

\section{VEGF pathway and VEGF gene polymorphisms}

VEGF expression plays a central role in the pathogenesis of DR. The upregulation of VEGF in the eyes of patients with diabetes is associated with breakdown of the blood-retinal barrier and increased vascular permeability. ${ }^{68}$ This leads to clinical manifestations of retinopathy. Higher levels of VEGF in the vitreous are correlated with increased severity of macular edema and DR. ${ }^{69,70}$

SNPs in the VEGF gene and its polymorphisms are of particular interest because therapy of DR largely focuses on anti-VEGF drugs.

The VEGF gene is located on chromosome $6 \mathrm{p} 21.3$ and is highly polymorphic as demonstrated in previous studies..$^{71-73}$ Of particular interest is the VEGF gene $C-634 G$ polymorphism rs2010963 in the 5-untranslated region. Studies including Japanese and Slovenian populations suggest strong association of this polymorphism with development of macular edema. ${ }^{70,74,75}$ Recent study in an Egyptian cohort of 392 patients demonstrated that the $C C$ genotype of $C-634 G$ polymorphism resulted in a significant risk for developing macular edema independently of the grade of DR. ${ }^{76}$ The $-634 G$ to $C$ substitution enhances VEGF expression. ${ }^{77}$

Many SNPs in the VEGF gene have been identified to be associated with the development of DR. Studies that have tested the role of VEGF gene polymorphisms in patients with DR conclude that patients with the $C C$ genotype have a higher level of VEGF in serum comparing the $C G$ and the $G G$ genotypes. The $C C$ genotype is associated with more favorable response to anti-VEGF therapy, $76 \%$ compared to the $C G(23 \%)$ and $G G$ genotype $(0.0 \%)$. The $G G$ phenotype has been found to be an independent predictor of neovascularization and development of proliferative DR. ${ }^{78}$
A recent study found an increased association of DR with the $C A$ genotype of the -2578 polymorphism. ${ }^{79}$ This polymorphism is also located in the promoter region. A meta-analysis including a number of case-control studies suggested an association between the $-2578 \mathrm{C} / \mathrm{A}$ polymorphism and DR in various ethnic groups except the Caucasian population. ${ }^{80}$ Another meta-analysis studying the association of the VEGF gene polymorphisms with DR found that retinopathy is associated with the VEGF gene $-460 T / C$ polymorphism but not the $-2578 \mathrm{C} / \mathrm{A}$ polymorphism. ${ }^{81}$ SNPs in the splicing region have also shown to be associated with DR. These include the SRp55 2994 polymorphism that controls alternative splicing of VEGF pre-RNA exon. Such properties may affect the balance between pro- and antiangiogenic VEGF isoforms. ${ }^{82}$

The VEGF-A gene structure and its associated major polymorphisms associated with DR are summarized in Figure 2. There is, indeed, a need for additional studies in confirming the role of these polymorphisms in patients with DR and DME. The aim of the studies, which should evaluate genetic polymorphisms and mutations involving a variety of loci on the human genome, is to be able to comprehensively identify all the potential pharmacogenomics markers for poor prognosis in DR. While pharmacogenomic markers have been identified to a great extent in ocular diseases such as age-related macular degeneration and glaucoma, information on DR is not very definitive. Table 1 summarizes a list of potential pharmacogenomic markers that have been identified, but we still need further evidences before they can be clinically applicable.

\section{Genetic basis of response to treatment}

With the knowledge that there are a number of genetic polymorphisms associated with the development of DR, it may be plausible that these polymorphisms could be responsible, at least partly, for variable response to anti-VEGF agents. Higher levels of VEGF associated with certain genetic compositions and polymorphisms in the VEGF gene itself

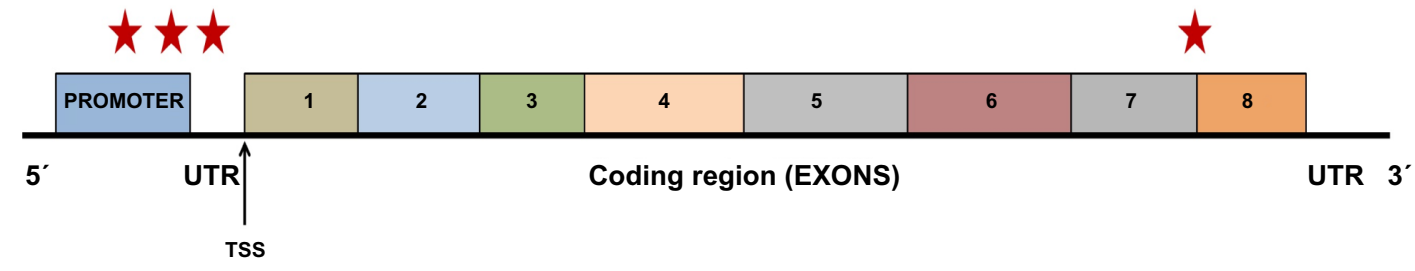

Figure 2 Structure and functional anatomy of the vascular endothelial growth factor-A (VEGF-A) gene.

Notes: The primary structure consists of the upstream promoter region followed by the $5^{\prime}$ untranslated region (UTR). There are eight exons in the coding region of the VEGF-A gene with the transcription start sequence (TSS) near the Exon I. The red stars represent the most common locations of the genetic polymorphisms of VEGF gene associated with DR. From left to right, the stars represent the locations of $-2578 \mathrm{C} / \mathrm{A}$ polymorphism, followed by $1498 \mathrm{C} / \mathrm{T}$ ( $-460 \mathrm{C} / \mathrm{T}$ ) polymorphism located in the promoter region; to their right is the location of the most important polymorphism, ie, $-634 G / C(405 \mathrm{G} / \mathrm{C})$, in the $5^{\prime}$ UTR region. The red star on the right side indicates certain splice site mutations that may be responsible for tilting the balance toward proangiogenesis due to alternative splicing mechanism. 
may indicate that, in order to achieve clinical benefit, either improvisation in the dosing regimen or combination therapy (of different targets) may be essential.

There is very little information available regarding the efficacy of various anti-VEGF agents used to treat DME based on the genetic profile of patients. On the other hand, there have been studies that evaluated such questions for AMD. ${ }^{83-85}$ The large multicenter CATT study evaluated the response of anti-VEGF treatment in 835 patients based on VEGF gene polymorphisms. ${ }^{86}$ The study could not conclusively identify any pharmacogenetic associations between gene SNPs and response to different anti-VEGF therapies. Current literature does not provide adequate information of pharmacogenetic associations in patients with DR.

On the other hand, it has been identified that there may be signaling pathways and abnormal gene expressions in patients with DR that are nonresponsive to therapy. In a study by Dabir et al, ${ }^{87}$ a difference in the gene expression was found between responders and nonresponders to treatment. More than 60 genes were upregulated and approximately 50 downregulated in patients with DR who were nonresponsive to therapy. Identifying the specific signaling pathway involved in DR at different stages of retinopathy and in response to therapy may provide insights that can help to solve the puzzle between responders and nonresponders.

Responders to treatment showed dramatic decrease in the extracellular matrix receptor gene and notable decrease in the transforming growth factor beta (TGF- $\beta$ ), while no changes were observed in these genes in the nonresponder group. Nonresponders, on the other hand, demonstrated increased expression of cellular adhesion molecules, WNT signaling pathway (which is implicated in diabetic complications such as vascular leakage and retinal neovascularization), several transcription factors, as well as stress-related genes.
In addition to signaling pathways, patients with DR are known to have altered and mitigated genetic expression of antioxidant enzymes. ${ }^{88}$ There are a variety of microRNAs (miRNAs) that are implicated in a variety of pathophysiological processes responsible for changes of DR. miRNAs control posttranscriptional gene expression and are important potential mediator and biomarker of diabetic complications and response to conventional therapy. ${ }^{89,90}$

Thus, the benefit in the response to antiangiogenic therapy may be limited due to redundancy of the VEGF target, thereby making the VEGF "resistant" to a particular therapeutic agent. ${ }^{91}$ The summary of the pharmacogenomic basis for nonresponse or suboptimal response in certain cohorts of patients is elucidated in Figure 3.

\section{Personalized medicine in diabetic retinopathy}

With advances in prospective, genetic, diagnostic, and therapeutic strategies for managing patients with DR, personalized treatment of patients with DR may soon be coming to the clinics. It may be possible to intervene early in patients identified to be at high genetic or phenotypic risk of progression, or in those who have a high risk of nonresponse to available therapies. ${ }^{92}$

Due to the enormous amount of financial constraints and health care cost concerns, research is now focusing on individualizing health care strategies based on extensive data available from studies. ${ }^{93}$ Through recognition of genomic biomarkers to identify patients at risk who may be incomplete responders or may not respond at all, innovative and early treatment options may be tailored for better outcomes. ${ }^{94}$ The ever-increasing burden of diabetes and its microvascular complications makes it very relevant to introduce the concept of personalized health care for this disease.
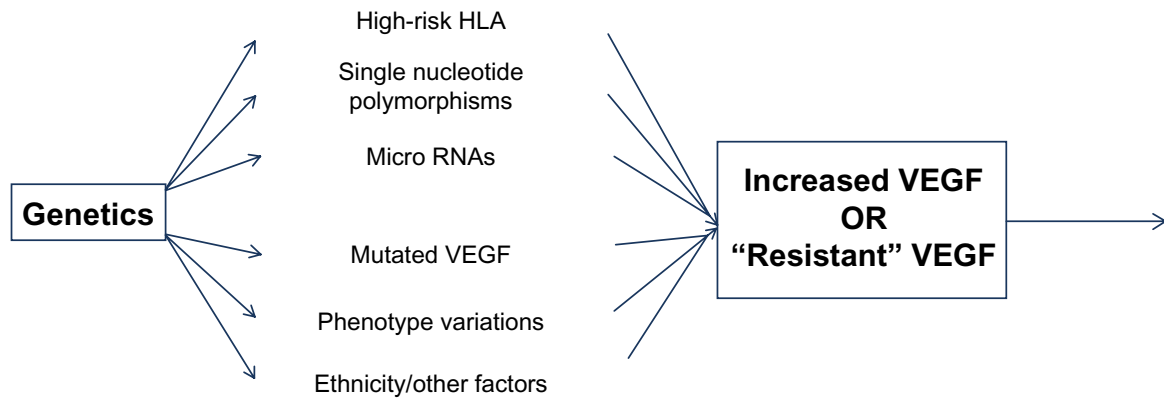

\section{Suboptimal or non-responder}

Figure 3 Summary of the most important pathways that may be responsible for variability of response from patient to patient in diabetic retinopathy (DR).

Notes: Genetic factors are proposed to play a central role in the pharmacological variation in response. Evidences from linkage analysis and human leucocyte antigen (HLA) studies, genome-wide association analysis, and population studies have strengthened this theory. In addition, mutations in VEGF gene and phenotype variations in DR may directly or indirectly increase the VEGF expression and its downstream effects on the retina. This ultimately results in poor response or no response at all in certain groups of patients to conventional anti-VEGF therapy. Because of the large number of factors that may lead to this undesirable state, there remains an unmet need for individualized therapeutic approach in patients with DR. 
Prevention of difficult-to-treat entities such as macular edema, iris and retinal neovascularization, and high-risk proliferative DR may become possible by early characterization of genomic features in every individual.

Personalized medicine in DR must also focus on individualization of glycemic target control, $\mathrm{HbA}_{1 \mathrm{c}}$ levels, blood pressure, and lipid-lowering strategies. There has been only modest progress in the pharmacogenomics of glucoselowering medications. ${ }^{90}$ Largely, the treatment of diabetes thus far remains empirical. ${ }^{95}$

Because of the wide variation in the clinical presentation, progression, and complications of DR, certainly a tailored therapeutic approach may be more effective. Personalized medicine can be also helpful in DR prediction and prevention. With advances in the identification of potential genetic associations of high-risk genes such as the $1704 T$ allele (RAGE gene $)^{96}$ and MTHFR 677C/T polymorphisms, ${ }^{97-99}$ data from proteomics and genomics may soon become relevant in clinical practice. ${ }^{100}$

\section{Clinical developments in treatment strategies based on pharmacogenomics}

The availability of information on various genetic influences on the incidence and severity of DR has enabled newer treatment options targeting molecular pathways to be on the horizon. Studies have been initiated in order to target alternate pathways, such as the insulin-like growth factor pathway and tyrosine kinase (TIE-2) pathway, which may be overactive in certain sets of patients based on their genetic composition. ${ }^{101,102}$

RNA interference (RNAi) technology has been used to potentially identify newer therapeutic targets for DR. ${ }^{103}$ RNAi allows silencing of practically any gene that may be overactive and responsible for phenotype manifestations resulting in disease. Such properties provide a promising strategy to treat diseases such as DR or DME.

Gene therapy for DR is still in its infancy. Animal studies have been initiated to deliver targeted molecules using adeno-associated virus to improve manifestations of DR with success. ${ }^{104,105}$ There have been no definitive data to support full clinical usage.

\section{Future of pharmacogenomics and personalized medicine in diabetic retinopathy}

The era of pharmacogenomics will undoubtedly allow tailoring treatment based on the individual's genetic profile.
Such a critical step will help to select the best therapy for the patient that will aid achieving the best visual outcome at the least possible cost. Future research strategies focusing on the identification of more phenotypic variations in DR based on clinical characteristics of the disease are certainly very relevant. In addition, consolidation of knowledge on genomic biomarkers of DR associated with suboptimal treatment response is necessary. It is imperative for clinical trials focusing on DR to analyze the possible reasons behind incomplete response or no response.

There have been advances in pharmacogenomics in other ocular diseases such as AMD and glaucoma. Therefore, further knowledge on the polymorphisms of the VEGF gene in DR and development of newer molecules to target the "resistant" allele may help improve visual outcomes in a larger number of patients. The level of evidence from various studies and practice guidelines will continue to evolve as more research is conducted in the field of pharmacogenomics.

\section{Disclosure}

Quan Dong Nguyen and Diana V. Do serve on the Scientific Advisory Boards for Genentech, Inc. and Regeneron, Inc. The authors report no other conflicts of interest in this work.

\section{References}

1. International Diabetes Federation. IDF Diabetes Atlas. 5th ed. 2011. Available from: http://www.idf.org/diabetesatlas.

2. Bourne RR, Stevens GA, White RA, et al; Vision Loss Expert Group. Causes of vision loss worldwide, 1990-2010: a systematic analysis. Lancet Glob Health. 2013;1(6):e339-e349.

3. Ahmadieh H, Shoeibi N, Entezari M, Monshizadeh R. Intravitreal bevacizumab for prevention of early postvitrectomy hemorrhage in diabetic patients: a randomized clinical trial. Ophthalmology. 2009;116(10):1943-1948.

4. Chen E, Looman M, Laouri M, et al. Burden of illness of diabetic macular edema: literature review. Curr Med Res Opin. 2010;26(7): $1587-1597$.

5. Nguyen QD, Brown DM, Marcus DM, et al; RISE and RIDE Research Group. Ranibizumab for diabetic macular edema: results from 2 phase III randomized trials: RISE and RIDE. Ophthalmology. 2012;119(4):789-801.

6. Abouammoh MA. Ranibizumab injection for diabetic macular edema: meta-analysis of systemic safety and systematic review. Can J Ophthalmol. 2013;48(4):317-323.

7. Bandello F, Casalino G, Loewenstein A, Goldstein M, Pelayes D, Battaglia Parodi M. Pharmacological approach to diabetic macular edema. Ophthalmic Res. 2014;51(2):88-95.

8. Boyer DS, Hopkins JJ, Sorof J, Ehrlich JS. Anti-vascular endothelial growth factor therapy for diabetic macular edema. Ther Adv Endocrinol Metab. 2013;4(6):151-169.

9. Patelli F, Radice P, Giacomotti E. Diabetic macular edema. Dev Ophthalmol. 2014;54:164-173.

10. Yang J, Wang X, Fuh G, et al. Comparison of binding characteristics and in vitro activities of three inhibitors of vascular endothelial growth factor A. Mol Pharm. 2014;11(10):3421-3430.

11. Stewart MW, Rosenfeld PJ. Predicted biological activity of intravitreal VEGF Trap. Br J Ophthalmol. 2008;92(5):667-668. 
12. Rajendram R, Fraser-Bell S, Kaines A, et al. A 2-year prospective randomized controlled trial of intravitreal bevacizumab or laser therapy (BOLT) in the management of diabetic macular edema: 24-month data: report 3. Arch Ophthalmol. 2012;130(8):972-979.

13. Do DV, Schmidt-Erfurth U, Gonzalez VH, et al. The DA VINCI Study: phase 2 primary results of VEGF Trap-Eye in patients with diabetic macular edema. Ophthalmology. 2011;118(9):1819-1826.

14. Martin DF, Maguire MG, Ying GS, Grunwald JE, Fine SL, Jaffe GJ. Ranibizumab and bevacizumab for neovascular age-related macular degeneration. N Engl J Med. 2011;364(20):1897-1908.

15. Korobelnik JF, Do DV, Schmidt-Erfurth U, et al. Intravitreal aflibercept for diabetic macular edema. Ophthalmology. 2014.

16. Nguyen QD, Shah SM, Khwaja AA, et al; READ-2 Study Group. Two-year outcomes of the ranibizumab for edema of the mAcula in diabetes (READ-2) study. Ophthalmology. 2010;117(11):2146-2151.

17. Massin P, Bandello F, Garweg JG, et al. Safety and efficacy of ranibizumab in diabetic macular edema (RESOLVE Study): a 12-month, randomized, controlled, double-masked, multicenter phase II study. Diabetes Care. 2010;33(11):2399-2405.

18. Mitchell P, Bandello F, Schmidt-Erfurth U, et al; RESTORE Study Group. The RESTORE study: ranibizumab monotherapy or combined with laser versus laser monotherapy for diabetic macular edema. Ophthalmology. 2011;118(4):615-625.

19. Campochiaro PA, Brown DM, Pearson A, et al; FAME Study Group Sustained delivery fluocinolone acetonide vitreous inserts provide benefit for at least 3 years in patients with diabetic macular edema. Ophthalmology. 2012;119(10):2125-2132.

20. Boyer DS, Yoon YH, Belfort R Jr, et al; Ozurdex MEAD Study Group. Three-year, randomized, sham-controlled trial of dexamethasone intravitreal implant in patients with diabetic macular edema. Ophthalmology. 2014;121(10):1904-1914.

21. Lobo CL, Bernardes RC, Figueira JP, de Abreu JR, Cunha-Vaz JG. Three-year follow-up study of blood-retinal barrier and retinal thickness alterations in patients with type 2 diabetes mellitus and mild nonproliferative diabetic retinopathy. Arch Ophthalmol. 2004;122(2):211-217.

22. Nunes S, Ribeiro L, Lobo C, Cunha-Vaz J. Three different phenotypes of mild nonproliferative diabetic retinopathy with different risks for development of clinically significant macular edema. Invest Ophthalmol Vis Sci. 2013;54(7):4595-4604.

23. Cunha-Vaz J, Ribeiro L, Lobo C. Phenotypes and biomarkers of diabetic retinopathy. Prog Retin Eye Res. 2014;41:90-111.

24. Ješić M, Sajić S, Ješić M, et al. Microalbuminuria in relation to metabolic control and blood pressure in adolescents with type 1 diabetes. Archives of medical science. 2011;7(6):1037-1041.

25. Arar NH, Freedman BI, Adler SG, et al; Family Investigation of Nephropathy and Diabetes Research Group. Heritability of the severity of diabetic retinopathy: the FIND-Eye study. Invest Ophthalmol Vis Sci. 2008;49(9):3839-3845.

26. Chen JL, Luviano DM, Chen JC, Yu F, Sarraf D. Comparison of diabetic retinopathy phenotype between Latinos and Blacks. J Diabetes Complications. 2009;23(6):371-375.

27. Yohannan J, Bittencourt M, Sepah YJ, et al. Association of retinal sensitivity to integrity of photoreceptor inner/outer segment junction in patients with diabetic macular edema. Ophthalmology. 2013;120(6): 1254-1261.

28. Cunha-Vaz J. Phenotypes and biomarkers of diabetic retinopathy. Personalized medicine for diabetic retinopathy: the Weisenfeld award. Invest Ophthalmol Vis Sci. 2014;55(8):5412-5419.

29. Bai Y, Ma JX, Guo J, et al. Muller cell-derived VEGF is a significant contributor to retinal neovascularization. J Pathol. 2009;219(4): 446-454.

30. Hietala K, Forsblom C, Summanen P, Groop PH. Heritability of proliferative diabetic retinopathy. Diabetes. 2008;57(8):2176-2180.

31. Clustering of long-term complications in families with diabetes in the diabetes control and complications trial. The Diabetes Control and Complications Trial Research Group. Diabetes. 1997;46(11): 1829-1839.
32. Simo-Servat O, Hernandez C, Simo R. Genetics in diabetic retinopathy: current concepts and new insights. Curr Genomics. 2013;14(5): 289-299.

33. Grassi MA, Tikhomirov A, Ramalingam S, et al. Replication analysis for severe diabetic retinopathy. Invest Ophthalmol Vis Sci. 2012;53(4): 2377-2381.

34. Huang YC, Lin JM, Lin HJ, et al. Genome-wide association study of diabetic retinopathy in a Taiwanese population. Ophthalmology. 2011;118(4):642-648

35. Fu YP, Hallman DM, Gonzalez VH, et al. Identification of diabetic retinopathy genes through a genome-wide association study among Mexican-Americans from Starr County, Texas. J Ophthalmol. 2010; 2010:ii:861291.

36. Imperatore G, Hanson RL, Pettitt DJ, Kobes S, Bennett PH, Knowler WC. Sib-pair linkage analysis for susceptibility genes for microvascular complications among Pima Indians with type 2 diabetes. Pima Diabetes Genes Group. Diabetes. 1998;47(5):821-830.

37. Looker HC, Nelson RG, Chew E, et al. Genome-wide linkage analyses to identify Loci for diabetic retinopathy. Diabetes. 2007;56(4):1160-1166.

38. Rand LI, Krolewski AS, Aiello LM, Warram JH, Baker RS, Maki T. Multiple factors in the prediction of risk of proliferative diabetic retinopathy. N Engl J Med. 1985;313(23):1433-1438.

39. Cruickshanks KJ, Vadheim CM, Moss SE, et al. Genetic marker associations with proliferative retinopathy in persons diagnosed with diabetes before $30 \mathrm{yr}$ of age. Diabetes. 1992;41(7):879-885.

40. Abhary S, Hewitt AW, Burdon KP, Craig JE. A systematic metaanalysis of genetic association studies for diabetic retinopathy. Diabetes. 2009;58(9):2137-2147.

41. Chiu C, Moss CF. The role of the external ear in vertical sound localization in the free flying bat, Eptesicus fuscus. J Acoust Soc Am. 2007;121(4):2227-2235.

42. Hudson BI, Stickland MH, Futers TS, Grant PJ. Effects of novel polymorphisms in the RAGE gene on transcriptional regulation and their association with diabetic retinopathy. Diabetes. 2001;50(6):1505-1511.

43. Tong Z, Yang Z, Patel S, et al; Genetics of Diabetes and Diabetic Complication Study Group. Promoter polymorphism of the erythropoietin gene in severe diabetic eye and kidney complications. Proc Natl Acad Sci U S A. 2008;105(19):6998-7003.

44. Cho SE, Hong KS, Shin GJ, Chung WS. The methylenetetrahydrofolate reductase $\mathrm{C} 677 \mathrm{~T}$ gene mutation is associated with hyperhomocysteinemia, cardiovascular disease and plasma B-type natriuretic peptide levels in Korea. Clinical Chemistry and Laboratory Medicine. 2006;44(9): 1070-1075.

45. Nakai K, Itoh C, Nakai K, Habano W, Gurwitz D. Correlation between C677T MTHFR gene polymorphism, plasma homocysteine levels and the incidence of CAD. Am J Cardiovasc Drugs. 2001;1(5):353-361.

46. Malaguarnera G, Gagliano C, Giordano M, et al. Homocysteine serum levels in diabetic patients with non proliferative, proliferative and without retinopathy. Biomed Res Int. 2014;2014:191497.

47. Aydemir O, Türkçüoğlu P, Güler M, et al. Plasma and vitreous homocysteine concentrations in patients with proliferative diabetic retinopathy. Retina. 2008;28(5):741-743.

48. Goldstein M, Leibovitch I, Yeffimov I, Gavendo S, Sela BA, Loewenstein A. Hyperhomocysteinemia in patients with diabetes mellitus with and without diabetic retinopathy. Eye. 2004;18(5):460-465.

49. Liang S, Pan $\mathrm{M}, \mathrm{Hu} \mathrm{N}$, et al. Association of angiotensin-converting enzyme gene $2350 \mathrm{G} / \mathrm{A}$ polymorphism with diabetic retinopathy in Chinese Han population. Mol Biol Rep. 2013;40(1):463-468.

50. Manea SA, Robciuc A, Guja C, Heltianu C. Identification of gene variants in NOS3, ET-1 and RAS that confer risk and protection against microangiopathy in type 2 diabetic obese subjects. Biochem Biophys Res Commun. 2011;407(3):486-490.

51. dos Santos KG, Canani LH, Gross JL, Tschiedel B, Souto KE, Roisenberg I. The $-106 \mathrm{CC}$ genotype of the aldose reductase gene is associated with an increased risk of proliferative diabetic retinopathy in Caucasian-Brazilians with type 2 diabetes. Mol Genet Metab. 2006;88(3):280-284. 
52. Wang J, Yang MM, Li YB, Liu GD, Teng Y, Liu XM. Association of $\mathrm{CFH}$ and CFB gene polymorphisms with retinopathy in type 2 diabetic patients. Mediators Inflamm. 2013;2013:748435.

53. Chen M, Lin WR, Lu CH, et al. Chimerin 2 genetic polymorphisms are associated with non-proliferative diabetic retinopathy in Taiwanese type 2 diabetic patients. J Diabetes Complications. 2014;28(4):460-463.

54. Arndt C, Leclercq I, Nazeyrollas P, et al. Association of endothelial lipase Thr111Ile polymorphism with proliferative retinopathy in type 2 diabetes patients. Diabetes and Metabolism. 2014.

55. Taverna MJ, Sola A, Guyot-Argenton C, et al. eNOS4 polymorphism of the endothelial nitric oxide synthase predicts risk for severe diabetic retinopathy. Diabet Med. 2002;19(3):240-245.

56. Abhary S, Burdon KP, Casson RJ, Goggin M, Petrovsky NP, Craig JE. Association between erythropoietin gene polymorphisms and diabetic retinopathy. Arch Ophthalmol. 2010;128(1):102-106.

57. Gong JY, Deng DT, Sun YH. Association of platelet glycoprotein receptor alpha2beta1 integrin and glycoprotein IIIa gene polymorphisms with diabetic retinopathy: evidence from 3007 subjects. Curr Eye Res. 2014;30:1-8.

58. Katakami N, Matsuhisa M, Kaneto H, et al. Monocyte chemoattractant protein-1 (MCP-1) gene polymorphism as a potential risk factor for diabetic retinopathy in Japanese patients with type 2 diabetes. Diabetes Res Clin Pract. 2010;89(1):e9-e12.

59. Yigit S, Karakus N, Inanir A. Association of MTHFR gene C677T mutation with diabetic peripheral neuropathy and diabetic retinopathy. Mol Vis. 2013;19:1626-1630.

60. Mankoc Ramus S, Kumse T, Globocnik Petrovic M, Petrovic D, Cilensek I. SNP rs2073618 of the osteoprotegerin gene is associated with diabetic retinopathy in Slovenian patients with type 2 diabetes. Biomed Res Int. 2013;2013:364073.

61. Ng ZX, Kuppusamy UR, Iqbal T, Chua KH. Receptor for advanced glycation end-product (RAGE) gene polymorphism 2245G/A is associated with pro-inflammatory, oxidative-glycation markers and sRAGE in diabetic retinopathy. Gene. 2013;521(2):227-233.

62. Zhang HM, Chen LL, Wang L, et al. Association of 1704G/T and G82S polymorphisms in the receptor for advanced glycation end products gene with diabetic retinopathy in Chinese population. $J$ Endocrinol Invest. 2009;32(3):258-262.

63. Sobrin L, Green T, Sim X, et al; Family Investigation of Nephropathy and Diabetes-Eye Research Group, Wellcome Trust Case Control Consortium 2. Candidate gene association study for diabetic retinopathy in persons with type 2 diabetes: the Candidate gene Association Resource (CARe). Invest Ophthalmol Vis Sci. 2011;52(10):7593-7602.

64. Luo J, Zhao L, Chen AY, et al. TCF7L2 variation and proliferative diabetic retinopathy. Diabetes. 2013;62(7):2613-2617.

65. Brondani LA, de Souza BM, Duarte GC, et al. The UCP1 -3826A/G polymorphism is associated with diabetic retinopathy and increased UCP1 and MnSOD2 gene expression in human retina. Invest Ophthalmol Vis Sci. 2012;53(12):7449-7457.

66. Crispim D, Fagundes NJ, dos Santos KG, et al. Polymorphisms of the UCP2 gene are associated with proliferative diabetic retinopathy in patients with diabetes mellitus. Clin Endocrinol. 2010;72(5): 612-619.

67. Han L, Zhang L, Xing W, et al. The associations between VEGF gene polymorphisms and diabetic retinopathy susceptibility: a meta-analysis of 11 case-control studies. J Diabetes Res. 2014;2014:805801.

68. Ishida S, Usui T, Yamashiro K, et al. VEGF164 is proinflammatory in the diabetic retina. Invest Ophthalmol Vis Sci. 2003;44(5):2155-2162.

69. Funatsu H, Yamashita H, Sakata K, et al. Vitreous levels of vascular endothelial growth factor and intercellular adhesion molecule 1 are related to diabetic macular edema. Ophthalmology. 2005;112(5):806-816.

70. Petrovic MG, Korosec P, Kosnik M, et al. Local and genetic determinants of vascular endothelial growth factor expression in advanced proliferative diabetic retinopathy. Mol Vis. 2008;14:1382-1387.

71. Vincenti V, Cassano C, Rocchi M, Persico G. Assignment of the vascular endothelial growth factor gene to human chromosome $6 \mathrm{p} 21.3$. Circulation. 1996;93(8):1493-1495.
72. Brogan IJ, Khan N, Isaac K, Hutchinson JA, Pravica V, Hutchinson IV. Novel polymorphisms in the promoter and 5' UTR regions of the human vascular endothelial growth factor gene. Hum Immunol. 1999;60(12): $1245-1249$.

73. Stevens A, Soden J, Brenchley PE, Ralph S, Ray DW. Haplotype analysis of the polymorphic human vascular endothelial growth factor gene promoter. Cancer Res. 2003;63(4):812-816.

74. Watson CJ, Webb NJ, Bottomley MJ, Brenchley PE. Identification of polymorphisms within the vascular endothelial growth factor (VEGF) gene: correlation with variation in VEGF protein production. Cytokine. 2000;12(8):1232-1235.

75. Awata T, Kurihara S, Takata N, et al. Functional VEGF C-634G polymorphism is associated with development of diabetic macular edema and correlated with macular retinal thickness in type 2 diabetes. Biochem Biophys Res Commun. 2005;333(3):679-685.

76. El-Shazly SF, El-Bradey MH, Tameesh MK. Vascular endothelial growth factor gene polymorphism prevalence in patients with diabetic macular oedema and its correlation with anti-vascular endothelial growth factor treatment outcomes. Clin Experiment Ophthalmol. 2014;42(4):369-378.

77. Huez I, Bornes S, Bresson D, Creancier L, Prats H. New vascular endothelial growth factor isoform generated by internal ribosome entry site-driven CUG translation initiation. Mol Endocrinol. 2001;15(12): 2197-2210.

78. Feghhi M, Nikzamir A, Esteghamati A, Mahmoudi T, Yekaninejad MS. Relationship of vascular endothelial growth factor (VEGF) $+405 \mathrm{G} / \mathrm{C}$ polymorphism and proliferative retinopathy in patients with type 2 diabetes. Transl Res. 2011;158(2):85-91.

79. Bleda S, De Haro J, Varela C, Esparza L, Ferruelo A, Acin F. Vascular endothelial growth factor polymorphisms are involved in the late vascular complications in Type II diabetic patients. Diab Vasc Dis Res. 2012;9(1):68-74.

80. Wang H, Cheng JW, Zhu LS, et al. Meta-analysis of association between the $-2578 \mathrm{C} / \mathrm{A}$ polymorphism of the vascular endothelial growth factor and retinopathy in type 2 diabetes in Asians and Caucasians. Ophthalmic Res. 2014;52(1):1-8.

81. Gong JY, Sun YH. Association of VEGF gene polymorphisms with diabetic retinopathy: a meta-analysis. PLoS One. 2013; 8(12):e84069.

82. Carter JG, Cherry J, Williams K, Turner S, Bates DO, Churchill AJ. Splicing factor polymorphisms, the control of VEGF isoforms and association with angiogenic eye disease. Curr Eye Res. 2011;36(4): 328-335.

83. Veloso CE, de Almeida LN, Recchia FM, Pelayes D, Nehemy MB. VEGF gene polymorphism and response to intravitreal ranibizumab in neovascular age-related macular degeneration. Ophthalmic Res. 2014;51(1): 1-8.

84. Lotery AJ, Gibson J, Cree AJ, et al; Alternative Treatments to Inhibit VEGF in Patients with Age-Related Choroidal Neovascularisation (IVAN) Study Group. Pharmacogenetic associations with vascular endothelial growth factor inhibition in participants with neovascular age-related macular degeneration in the IVAN Study. Ophthalmology. 2013;120(12):2637-2643

85. Abedi F, Wickremasinghe S, Richardson AJ, et al. Variants in the VEGFA gene and treatment outcome after anti-VEGF treatment for neovascular age-related macular degeneration. Ophthalmology. 2013;120(1):115-121.

86. Hagstrom SA, Ying GS, Pauer GJ, et al; Comparison of Age-Related Macular Degeneration Treatments Trials (CATT) Research Group. VEGFA and VEGFR2 gene polymorphisms and response to antivascular endothelial growth factor therapy: comparison of age-related macular degeneration treatments trials (CATT). JAMA Ophthalmol. 2014;132(5):521-527.

87. Dabir SS, Das D, Nallathambi J, Mangalesh S, Yadav NK, Schouten JS. Differential systemic gene expression profile in patients with diabetic macular edema: responders versus nonresponders to standard treatment. Indian J Ophthalmol. 2014;62(1):66-73. 
88. El-Bab MF, Zaki NS, Mojaddidi MA, Al-Barry M, El-Beshbishy HA. Diabetic retinopathy is associated with oxidative stress and mitigation of gene expression of antioxidant enzymes. Int J Gen Med. 2013;6: 799-806.

89. Mastropasqua R, Toto L, Cipollone F, Santovito D, Carpineto P, Mastropasqua L. Role of microRNAs in the modulation of diabetic retinopathy. Prog Retin Eye Res. 2014;43C:92-107.

90. Kato M, Castro NE, Natarajan R. MicroRNAs: potential mediators and biomarkers of diabetic complications. Free Radic Biol Med. 2013;64: 85-94.

91. Jain RK, Duda DG, Willett CG, et al. Biomarkers of response and resistance to antiangiogenic therapy. Nat Rev Clin Oncol. 2009;6(6): 327-338.

92. Snyderman R, Williams RS. Prospective medicine: the next health care transformation. Acad Med. 2003;78(11):1079-1084.

93. Chawla NV, Davis DA. Bringing big data to personalized healthcare: a patient-centered framework. J Gen Intern Med. 2013;28(Suppl 3): S660-S665.

94. Chen JJ, Lin WJ, Chen HC. Pharmacogenomic biomarkers for personalized medicine. Pharmacogenomics. 2013;14(8):969-980.

95. Inzucchi SE, Bergenstal RM, Buse JB, et al. Management of hyperglycemia in type 2 diabetes: a patient-centered approach: position statement of the American Diabetes Association (ADA) and the European Association for the Study of Diabetes (EASD). Diabetes Care. 2012;35(6):1364-1379.

96. Niu W, Qi Y, Wu Z, Liu Y, Zhu D, Jin W. A meta-analysis of receptor for advanced glycation end products gene: four well-evaluated polymorphisms with diabetes mellitus. Mol Cell Endocrinol. 2012;358(1): 9-17.
97. Niu W, Qi Y. An updated meta-analysis of methylenetetrahydrofolate reductase gene $677 \mathrm{C} / \mathrm{T}$ polymorphism with diabetic nephropathy and diabetic retinopathy. Diabetes Res Clin Pract. 2012;95(1):110-118.

98. Maeda M, Yamamoto I, Fukuda M, et al. MTHFR gene polymorphism is susceptible to diabetic retinopathy but not to diabetic nephropathy in Japanese type 2 diabetic patients. J Diabetes Complications. 2008;22(2):119-125.

99. Maeda M, Yamamoto I, Fukuda M, et al. MTHFR gene polymorphism as a risk factor for diabetic retinopathy in type 2 diabetic patients without serum creatinine elevation. Diabetes Care. 2003;26(2):547-548.

100. Glauber HS, Rishe N, Karnieli E. Introduction to personalized medicine in diabetes mellitus. Rambam Maimonides Med J. 2014;5(1):e0002.

101. Aerpio Therapeutics. The TIME-2 Study: A Phase 2 Study of AKB9778, A Novel Tie-2 Activator, in Patients with Diabetic Macular Edema; 2014. Available from: https://clinicaltrials.gov/ct2/show/ NCT02050828.

102. River Vision Development Corporation. A Phase 1, Open-Label Study of Teprotumumab in Patients with Diabetic Macular Edema (DME). 2014

103. Guzman-Aranguez A, Loma P, Pintor J. Small-interfering RNAs (siRNAs) as a promising tool for ocular therapy. Br J Pharmacol. 2013;170(4):730-747.

104. Vacca O, Darche M, Schaffer DV, et al. AAV-mediated gene delivery in Dp71-null mouse model with compromised barriers. Glia 2014;62(3):468-476.

105. Adhi M, Cashman SM, Kumar-Singh R. Adeno-associated virus mediated delivery of a non-membrane targeted human soluble CD59 attenuates some aspects of diabetic retinopathy in mice. PLoS One. 2013;8(10):e79661.
Pharmacogenomics and Personalized Medicine

\section{Publish your work in this journal}

Pharmacogenomics and Personalized Medicine is an international, peerreviewed, open access journal characterizing the influence of genotype on pharmacology leading to the development of personalized treatment programs and individualized drug selection for improved safety, efficacy and sustainability. This journal is indexed on the American Chemical

\section{Dovepress}

Society's Chemical Abstracts Service (CAS). The manuscript management system is completely online and includes a very quick and fair peer-review system, which is all easy to use. Visit http://www.dovepress. $\mathrm{com} /$ testimonials.php to read real quotes from published authors. 